\title{
La urbanización de las áreas periféricas en Santiago y Valparaíso: el papel de las relaciones de poder en el dibujo de la geografía socioresidencial
}

\section{Rodrigo Hidalgo.}

Instituto de Geografía, Pontificia Universidad Católica de Chile.

\section{Hugo Marcelo Zunino.}

Departamento de Ciencias Sociales, Universidad de La Frontera.

RESUMEN | Este trabajo constituye un esfuerzo por generar una mirada más comprensiva al fenómeno urbano; conjugando la geografía de lo visible y lo que se puede deducir a partir de la aplicación de métodos estadísticos con el análisis de los procesos sociales y las relaciones de que son intrínsecas a cualquier proceso de desarrollo urbano. El área de estudio comprende cinco comunas periféricas respecto al área metropolitana de Valparaíso y ocho comunas periféricas respecto al área metropolitana de Santiago. Basados en una perspectiva teórica que enfatiza conceptos como "regla social", "agente estructurado" y "poder", se aplica un análisis multi-escalar que utiliza fuentes primarias y secundarias. Se concluye que existe un fuerte centralismo en la toma de decisiones en el proceso de desarrollo urbano, particularmente en lo que se refiere a la política de vivienda social. Los habitantes de los conjuntos de vivienda social permanecen no sólo marginados socioterritorialmente, sino también en términos políticos, en cuanto a una participación ciudadana meramente formal y no efectiva.

PALABRAS CLAVE | Desarrollo urbano, gobierno local, política urbana, segregación

ABSTRACT | This paper constitutes an effort to generate a more comprehensive view of the urban phenomenon; bringing together geography of the visible and what is inferable through the application of statistical procedures with the analysis of power and social relations that are intrinsic to any urban development process. The study area compromises 5 peripheral municipalities in relation to greater Valparaiso and 8 peripheral municipalities in relation to greater Santiago. Based on a on a theoretical framework that emphasizes concepts such as 'social rule', 'structured agent' and 'power', we perform a multi-scalar analysis using primary and secondary sources. We conclude that there is a strong centralism in the urban decision making process, in particular in the social housing policy. The residents of social housing complexes appear not only marginalized in the socio-territorially, but also in the political sphere, in terms of a formal but not effective public participation.

KEY WORDS | Urban development, local government, urban policy, segregation.

Recibido el 21 de octubre de 2010, aprobado el 21 de marzo de 2011.

Correspondencia: Rodrigo Hidalgo, Instituto de Geografia, Pontificia Universidad Católica de Chile. Av. Vicuña Mackenna 4860, casilla 306-correo 22, código postal: 6904411, Santiago, Chile. Teléfono: 3547928. E-mail: hidalgo@geo.puc.cl | Hugo Marcelo Zunino, Departamento de Ciencias Sociales, Universidad de La Frontera, Av. Francisco Salazar 01145, casilla 45D, código postal: 4780000, Temuco, Chile. E-mail: hzunino@ufro.cl 


\section{Introducción: el territorio y los agentes}

La urbanización descontrolada y desregulada en las áreas periféricas en torno a las áreas metropolitanas de Santiago y Valparaíso (AMS y AMV) resulta un elemento del paisaje evidente que difícilmente pase desapercibido al observador atento. En efecto, conjuntos de vivienda social precarios se levantan en áreas que permanecen aisladas social y funcionalmente de conglomerados urbanos y en cuyas inmediaciones cobran importancia en cuanto a la ocupación del suelo las actividades primarias asociadas con la agricultura extensiva, muchas de ellas insertas desde algunos años en los circuitos económicos globales, como la vitivinicultura, por ejemplo. El explicativo principal de esta tipología de desarrollo urbano fragmentado es la aplicación de una política de vivienda social basada en subsidios a la demanda, dejando la localización de los conjuntos de vivienda social en manos de urbanistas privados que buscan incrementar y acelerar la acumulación de capital. Para reducir los costos, estos conjuntos tienden a localizarse en la periferia de los asentamientos urbanos consolidados (ver, por ejemplo, Hidalgo, 2007; Brain y Sabatini, 2006).

Diversos investigadores han puesto de manifiesto que esta modalidad de urbanización ha generado un sinnúmero de efectos sociales negativos, como carencia de infraestructura básica y el rompimiento de redes sociales de amistad y cooperación (ver, entre otros, Brain et al., 2007; Rodríguez y Sugranyes, 2005; Zunino \& Hidalgo, 2009). Asociado con lo anterior, se limita la entrada de los habitantes de estos conjuntos al mercado formal del trabajo, dada la fricción de la distancia que deben vencer en sus viajes diarios entre el lugar de residencia y el trabajo, acentuando el sentido tanto simbólico como material de marginalidad.

Cabe precisar, sin embargo, que las investigaciones sobre segregación sociorresidencial no pueden analizarse como una relación directa y determinista entre segregación y neoliberalismo. En un primer nivel de análisis, la segregación puede considerarse una actitud natural del ser humano, en tanto este tiende a vincularse social y espacialmente con gente que comparte similares comportamientos, visiones del mundo, estilos de vida y, en general, lo que se puede encapsular como una misma o similar cultura urbana. Por otra parte, la segregación no constituye una mera consecuencia de la operación del régimen capitalista en su versión neoliberal. Es así como en ciudades grades y medianas que se desarrollan al alero de otros regímenes (bajo un capitalismo más protegido con una fuerte intervención estatal o una variación particular de un régimen de corte socialista) la segregación también está presente y puede ser producto de factores que operan a una escala local o regional, entre los que podemos mencionar acceso diferencial al poder, pertenencia a determinado conglomerado ideológico y segregación étnica, por nombrar sólo algunos de los factores incidentes en la segregación que no son necesariamente propios de la estructura social capitalista.

Asimismo, la modalidad de configuración territorial descrita para el caso chileno va en paralelo con la construcción de condominios exclusivos en los lugares más favorecidos en términos de amenidades ambientales, seguridad y accesibili- 
dad. Esta forma de desarrollo urbano es resultante de la aplicación del Decreto con Fuerza de Ley no 3516 de 1980 que permite la subdivisión del suelo rústico en predios de $5.000 \mathrm{~m}^{2}$ en las zonas rurales. Estos complejos residenciales dirigidos principalmente a las clases con mayor poder adquisitivo se desarrollan al margen de los instrumentos formales que norman el uso del suelo y quedan exentos -por tanto- de los requisitos de dotación de obras básicas de urbanización, que se requieren para construcciones residenciales en zonas ubicadas en áreas urbanas establecidas sancionadas en los respectivos planes reguladores comunales. Muchos de estos condominios y "parcelaciones de agrado" se localizan a escasa distancia de los complejos de vivienda social. Sin embargo, la interacción social entre ambos grupos en la mayoría de los casos es baja o nula; lo cual es indicativo de que la segregación espacial está eventualmente disminuyendo (ver Sabatini, Cáceres y Cerda, 2001). mientras que la segregación social se mantiene o incluso puede estar aumentando. En muchos casos los condominios y parcelaciones constituyen fortificaciones autosustentables delimitadas espacialmente por cercos, muros y sistemas de vigilancia las 24 horas del día (ver trabajos contenidos en Hidalgo y De Mattos, 2007).

En Chile, en particular, y en Latinoamérica, en general, las investigaciones sobre el desarrollo urbano y la rápida extensión horizontal de las ciudades han adoptado en su gran mayoría una perspectiva neoestructuralista, centrando la atención analítica en descifrar la relación entre la reestructuración capitalista neoliberal, implementada a partir de la década de los ochenta, y los cambios urbanos experimentados en las grandes aglomeraciones urbanas (Zunino, 2002). Estas investigaciones han concluido -correctamente- que se ha generado un sinnúmero de efectos negativos entre los cuales se cuenta: la disfuncionalidad del sistema urbano resultante, la creciente segregación social, mayores dificultades de integrarse a los mercados formales de trabajo y altos niveles de cesantía en barriadas periféricas pobres (De Mattos, 1999, 2002a; Borsdorf \& Hidalgo, 2008). Sin bien la literatura especializada ha aportado antecedentes significativos sobre las problemáticas urbanas surgidas bajo el alero de las políticas de liberalización económica, es posible, necesario e imperativo realizar una lectura a la forma en que operan y se organizan los agentes sociales en la esfera local -la más inmediata-, pues son sus acciones (o inacciones) y los procesos sociales asociados los que sostienen la construcción de la realidad territorial que puede ser percibida por nuestros ojos y descrita mediante métodos estadísticos. La penetración neoliberal constituye uno de los factores que intervienen en la segregación, pero esto dista de ser una relación mecánica generalizable. A nuestro entender, para avanzar en una lectura más comprensiva del fenómeno urbano se debe poner el debido acento analítico en las prácticas sociales concretas que se desenvuelven bajo determinada estructura social o ideológica. En consecuencia, en esta investigación se avanza en descifrar las relaciones sociales y de poder que están detrás y sostienen la fabricación del paisaje urbano, rural-urbano y rural.

Por una parte, siguiendo la ruta marcada por las aportaciones clásicas, analizaremos información primaria detallada sobre el proceso de desarrollo urbano y los impactos socioeconómicos que se han dado en las comunas periféricas a las 
áreas metropolitanas de Santiago y Valparaíso (AMS y AMV, respectivamente). Para estudiar el proceso con una base empírica objetiva utilizaremos información pormenorizada sobre la localización de los complejos de vivienda social y los condominios construidos entre los años 1992 y 2005. Para profundizar esta línea de trabajo se establecerán relaciones entre la construcción de artefactos residenciales urbanos (condominios y complejos de vivienda social) con los cambios en la situación socioeconómica a nivel comunal. Para estimar cambios socioeconómicos a nivel comunal se utilizará un índice estandarizado construido en base a la información disponible en los Censos de Población y Vivienda de 1992 y 2002. Con este ejercicio se espera avanzar desde un análisis territorial deductivo-especulativo a uno inductivo-concreto basado en información primaria levantada por los propios investigadores.

Una segunda área del conocimiento en donde contribuye esta investigación es ofrecer una lectura del andamiaje institucional que está posibilitando el patrón de desarrollo urbano que describiremos. Si bien el proceso de desarrollo urbano tiene una dimensión "objetiva” que puede ser leída a través de la evolución de las construcciones en un espacio-tiempo determinado, no es menos cierto, insistimos, que la urbanización constituye un hecho social. Tomando esta perspectiva epistémica, el andamiaje institucional que permite la conformación de la geografía urbana "visible" u "objetiva" está constituido por diversos agentes -limitados y posibilitados por la estructura social (Giddens, 1984; Zunino, 2002, 2006) - que intentan avanzar intereses de distinta índole (económicos, sociales, políticos, institucionales, etc.). Dado lo anterior, el andamiaje institucional representa una particular "arquitectura de poder", en donde se puede leer una gama de tácticas y estrategias desplegadas para alcanzar metas asociadas con una gama de intereses (ver aportes de Darcy, 1999; Hamilton et al., 2004; Jacobs y Mancy, 1996; Ostrom, 1996). A pesar de que la literatura urbana latinoamericana ha relacionado coherentemente las relaciones entre el sistema económico y las transformaciones urbanas (Chion, 2002; De Mattos, 2001, 2002a, 2002b) queda por avanzar en cuanto a analizar las relaciones sociales implicadas en dichas transformaciones. Pocas investigaciones han puesto la atención analítica en la relación existente entre los procesos de toma de decisión y quienes mediante el despliegue de ciertas tácticas y estrategias configuran el territorio (en algunas de las dimensiones de este proceso ver los trabajos de Heinrichs, Nuissl y Rodríguez Seeger, 2009; Orellana, 2009 y Salazar, 2007). Esta línea de investigación ha sido trabajada con mayor profundidad por la literatura anglosajona interesada en descifrar las relaciones de poder entre actores públicos y privados con injerencia en materia de desarrollo urbano (Gendron, 2006; Goldsmith y Larsen, 2004; González y Healey, 2005; Mullin, 2004; entre otros)

El área de estudio que consideraremos en este trabajo son ocho comunas periféricas del AMS (Tiltil, Curacaví, El Monte, Talagante, Buin, Peñaflor, Paine e Isla de Maipo) y cinco comunas periféricas respecto al AMV (Quintero, Quillota, Olmué, Limache y Casablanca). La Figura 1 muestra el área de estudio. 
FIGURA 1 | Comunas de las periferias del AMS y AMV involucradas en el estudio

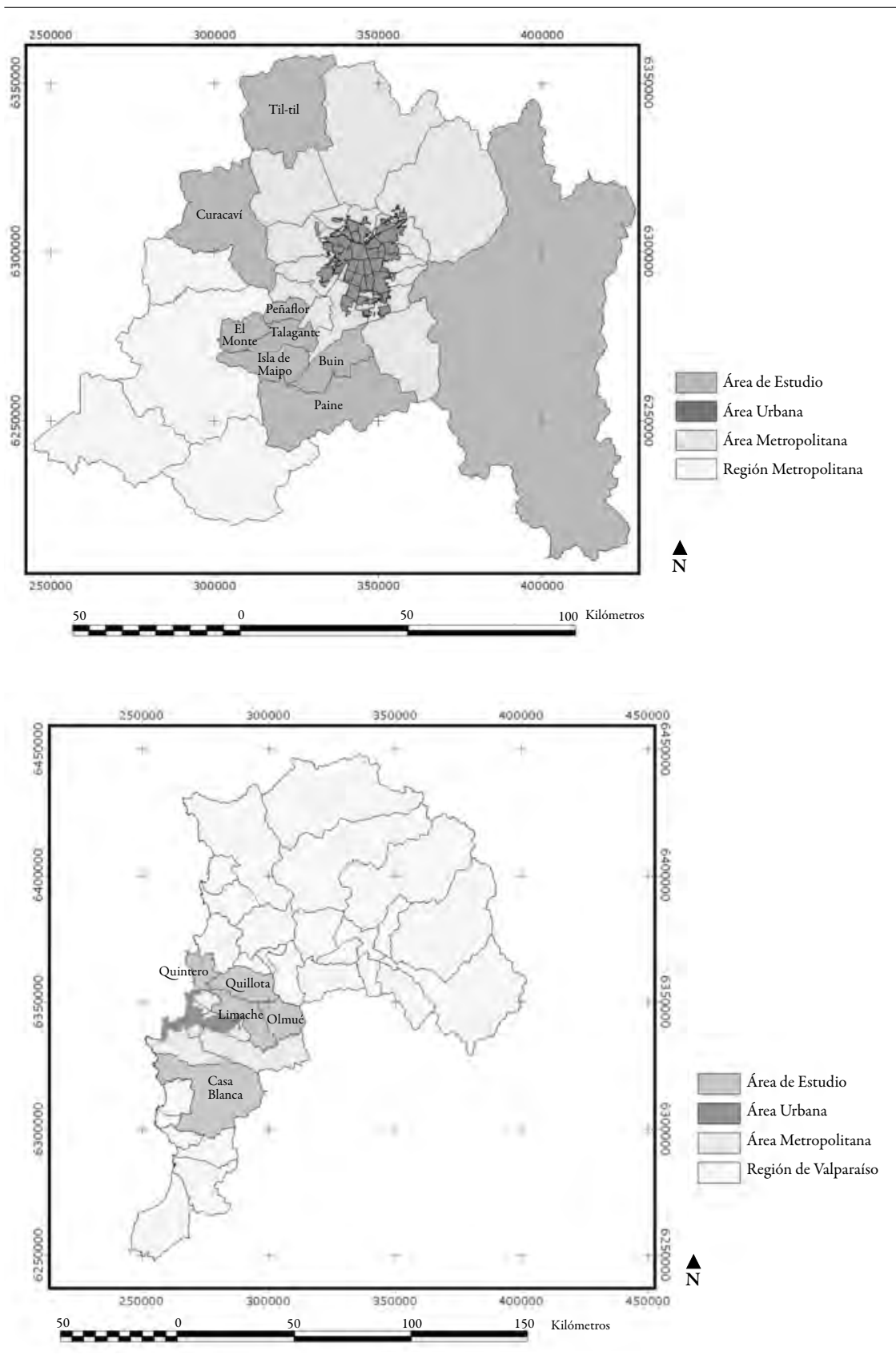

FUENTE ELABORACIÓN PROPIA. 
En la siguiente sección se desarrollará el marco teórico que fundamenta esta investigación, enfatizando aspectos conceptuales sobre el desarrollo urbano en Latinoamérica y los referentes teóricos utilizados para comprender cómo la ciudad representa un constructo social basado en relaciones de poder que se construyen entre actores estratégicos (Zunino, 2006). Basados en avances recientes en la literatura latinoamericana y anglosajona, en la tercera sección presentaremos la metodología que utilizaremos para alcanzar los objetivos propuestos. La cuarta sección presenta el desarrollo de la investigación. En la primera sub-sección de este cuarto acápite se ofrecerá un análisis riguroso sustentando por información primaria sobre los procesos urbanos que se están desenvolviendo en el área de estudio. En la segunda subsección se ofrecerá una lectura a las relaciones de poder intrínsecas a todo proceso de desarrollo urbano. Es importante en este punto hacer una salvedad que resulta importante. Cómo muchos "teóricos del poder" lo han mostrado, las relaciones de poder son mucho, complejas y operan a distintas escalas de análisis (Clegg, 1989; Foucault, 1980, 1995). En el caso particular de este estudio, que abarca una superficie significativa y hay un gran número de actores sociales involucrados, resulta impracticable analizar por completo la maquinaria del poder existente y en permanente cambio; este trabajo se limita a una mirada general en torno a dos escalas que nos parecen fundamentales para la identificación de los principales nodos en donde se establecen las relaciones de poder: nos referimos a las escalas nacional y local. En la escala nacional, el ejercicio del poder se ha visto fuertemente condicionado (pero no simplemente determinado) tanto por la penetración del sistema neoliberal como por la tecnificación de la política. Esto tiene, a nivel de especulación teórica, un fuerte impacto en cuanto a las posibilidades y restricciones existentes para que las comunidades locales ejerzan influencia en la toma de decisiones respecto al desarrollo urbano. Así, se ofrece una de las relaciones de poder más evidentes que se desenvuelven entre actores que operan en las escalas nacional y comunal. En la escala comunal, en particular, pondremos especial énfasis en examinar las relaciones que se desenvuelven en ámbitos más acotados territorialmente, centrando preferente el análisis en las relaciones de poder que se establecen entre los beneficiarios de los programas de vivienda social y las autoridades locales o municipales.

Consistentemente con la estructura y objetivos del trabajo, en la última sección -reflexiones finales- nos centraremos en caracterizar el desarrollo urbano en el área de estudio y su influencia sobre las condiciones socioeconómicas de la población y en sintetizar las principales relaciones de poder intrínsecas a la construcción social del territorio.

\section{Desarrollo urbano, capitalismo y el ejercicio del poder}

\section{Modelando el crecimiento de las ciudades}

El desarrollo urbano tiene una dimensión "objetiva”, la cual puede leerse y analizarse en base, por ejemplo, a técnicas y métodos basados en sistemas de información 
geográfica, percepción remota y en el análisis estadístico de datos cuantitativos. Más aún, esta información se puede correlacionar con la evolución de los parámetros socioeconómicos de la población a través del tiempo, lo cual hace posible examinar, entre otros temas, cómo las transformaciones urbanas afectan -o no- las condiciones de vida de la población. En este contexto, esta línea de investigación resulta esencial para determinar las consecuencias de los instrumentos de planificación territorial y los cambios en el paisaje urbano que estos generan sobre las condiciones de vida de una población dada. El conocimiento acabado de este tipo de fenómenos -avalados por indicadores duros que le den confiabilidad a los resultados del análisis- resulta esencial para cualquier tipo de investigación que pretenda extenderse sobre las transformaciones socioterritoriales que son inherentes a los procesos sociales, políticos y económicos que se desenvuelven simultáneamente en distintas escalas geográficas. Este trabajo considera la importancia de esta dimensión analítica en el caso particular del proceso de desarrollo urbano en el área de estudio. La particularidad de esta investigación es que enfatiza también el papel de los agentes que dibujan las geografías sociales resultantes a través del despliegue de una serie de tácticas y estrategias basadas en una determinada arquitectura institucional y de poder, en la cual ciertas "posiciones" o actores que poseen recursos para el ejercicio del poder construyen, reproducen y/o destruyen en el territorio sobre el cual toman sus decisiones.

\section{Capitalismo y poder}

Posiciones Marxistas y neoestructuralistas conciben a la ciudad como una cristalización de superestructuras económicas. Así, autores como Harvey (1978) comprenden la producción, reproducción y destrucción del paisaje urbano como el resultado de la operatoria del sistema capitalista, el cual necesariamente gatilla procesos que le dan el carácter y la forma a la sociedad contemporánea. Para este autor, la noción de "destrucción constructiva" y "anclaje espacial" son dos ejes centrales para comprender las transformaciones urbanas (ver aportes de González, 2005; González y Healey, 2005). En efecto, así como el capitalismo -en tanto sistema social operando como una "macroestructura", a un nivel general- está destinado a enfrentar continuas contradicciones, como cualquier otro sistema social similarmente el espacio geográfico es entendido como el reflejo de esta macroestructura y se ve enfrentado a una continua destrucción y reconstrucción, siendo imposible alcanzar un anclaje espacial, es decir, una forma espacial terminal que permita la acumulación de capital a través de largos periodos de tiempo. En este contexto, la llamada "ciudad postmoderna" - caracterizada por la fragmentación urbana, segregación socioespacial, el surgimiento de artefactos urbanos que replican a otros tiempos (siendo la ciudad de Las Vegas el ícono de este aspecto) y el control del espacio por los dueños del capital- es el reflejo de la transformación sociopolítica que caracteriza al capitalismo avanzado o lo que en Latinoamérica comúnmente se denomina neoliberalismo. Cabe aclarar, sin embargo, que los elementos que caracterizan a la 
ciudad postmoderna no son una mera cristalización del sistema social, como ya se argumentó en la sección inicial, sino que responden a una dialéctica global-local, razón por la cual los "males" de la ciudad contemporánea pueden encontrarse en diversos contextos socioestructurales e ideológicos.

Si bien existe una batería de estudios que han relacionado el modelo neoliberal con las transformaciones urbanas y el surgimiento de un número de patologías sociales (delincuencia, drogadicción, cesantía), esta perspectiva tiene la limitante de concebir al ser humano como un mero ente que reacciona a condicionamientos proveniente de la "macroestructura sociológica". El ser humano, argumentamos, retiene siempre la capacidad de resistir, oponerse, generar proyectos e iniciativas y, en última instancia, de acabar con su propia existencia. Para articular esta posición Giddens en 1984 acuñó la terminología de "agente estructurado": ni libre, ni esclavo; condicionado pero jamás determinado.

Si bien las disquisiciones teóricas de Giddens aparecen importantes para establecer una posición intermedia entre perspectivas que acentúan el rol de los agentes (voluntarismo, humanismo) y aquellas que le confieren un papel insigne a las estructuras sociales como factor de cambio socioespacial (estructuralismo, marxismo); el ejercicio del poder que es intrínseco a toda relación intersubjetiva, parece - en el trabajo de Giddens- atado a las estructuras generales de dominación, debilitando su propia construcción del "agente estructurado". Para resolver esta tensión en el trabajo de este conocido sociólogo se sugiere tomar una posición foucaultiana respecto del poder: Para Michel Foucault $(1980,1995)$ el poder no emana de una institución o sistema social, para que éste sea real, o más bien tenga efectos objetivables, tiene que ser ejercido a través de tácticas y estrategias que son diseñadas en forma consciente y predeterminada para avanzar determinados fines y propósitos que le son propios a ciertas colectividades e individuos. De ahí la importancia de estudiar las "gobermentalidades" (governmentalities, en inglés), es decir, las tecnologías de gobierno aplicadas para controlar el espacio y la sociedad. Hay que tener presente, que, como afirma Rose y Miller (1992), el control total nunca es posible, y son justamente estas fisuras en el sistema de control las que abren posibilidades para un cambio efectivo mediante acciones tendientes a modificar la arquitectura del poder existente.

Existe un último punto que es importante para sentar las bases para la aproximación metodológica que se empleará. Siguiendo las aportaciones teóricas Swyngedouw (1997, 2005), entre otros, las escalas geográficas no deben interpretarse como capas fijas, como rodajas que pueden analizarse independientemente unas de otras: las escalas geográficas son construcciones sociales que son creadas para alcanzar fines determinados y la articulación de una arquitectura de poder determinada. La escala regional, por ejemplo, no es "natural", muchas veces es un constructo político administrativo creado para facilitar el control sobre determinado ámbito geográfico, para lo cual se vale de una particular estructura organizativa formal que tiene los recursos para ejercer el poder en cierta unidad administrativa. 
Mientras que en algunos lugares, como en ciertos counties en Estados Unidos, la escala local constituye el ámbito de acción más importante a la hora de planificar el uso del territorio; en países más centralistas como Francia, es el Estado nacional quien comanda el proceso de desarrollo urbano. La existencia de escalas - en tanto constructos sociales- facilita y hace posible la circulación y articulación vertical del poder. Este "análisis multiescalar del poder" es recogido por autores como Clegg (1989) y González (2005) como esencial para analizar dinámicas de poder asociadas a las transformaciones urbanas. Si bien las escalas geográficas son construcciones sociales, ello no significa que sean inútiles para analizar la circulación del poder; muy por el contrario, dado el carácter multiescalar del poder éste "circula" a través de escalas geográficas que posibilitan el ejercicio del poder. Así, resulta indispensable establecer escalas geográficas funcionales: espacios de acción social y territorialmente acotados, los cuales disponen de un marco regulatorio y jurídico particular que establece las bases para el ejercicio del poder.

Si se afina más aún el análisis se puede llegar a estudiar lo que Foucault (1992) denomina la "microfísica del poder"; es decir, las acciones concretas de individuos y colectividades para afianzar el control social. Si bien lo extensivo de esta investigación no permitirá un análisis detallado de esta microfísica, no dejaremos de exponer algunos resultados parciales en cuanto al papel desempeñado por algunos actores estratégicos. El lector debe estar consciente de esta limitante y tener presente que existen condiciones macroestructurales que inciden en la configuración de determinadas relaciones de poder en la escala más inmediata, como lo es, por ejemplo, el hábitat residencial.

En suma, para avanzar en descifrar cómo se ejerce el poder en el desarrollo residencial del área de estudio se pretendió avanzar en: (a) identificar escalas funcionales de trabajo, (b) definir una herramienta heurística que nos permita analizar cómo el poder circula verticalmente, y (c) diseñar y aplicar una metodología de investigación para acceder a información primaria sobre cómo el poder está siendo ejercido en distintas escalas geográficas superpuestas e interrelacionadas.

\section{Aproximación metodológica}

Para analizar el desarrollo urbano-residencial del área de estudio entre los años 1992 y 2006 se realizó una recopilación de los complejos de vivienda social y condominios recepcionados en las Direcciones de Obras de las Municipalidades (DOM) del área de estudio. Posteriormente, se procedió a georreferenciar cada una de las obras y se recolectaron antecedentes acerca de las amenidades urbanas y superficie de cada complejo habitacional. Esta labor permitió generar tablas sobre el número de construcciones recepcionadas en el período 1992-2006 desagregadas a nivel comunal, con sus respectivas salidas cartográficas que permitiesen visualizar la situación que se encontró. Como segunda fase, se procedió a evaluar el status socioeconómico mediante el cálculo del Índice de Desarrollo Socioeconómico 
(IDS), el cual se estima a partir de la calidad de la vivienda, amenidades disponibles en el hogar y nivel de estudio del jefe de hogar ${ }^{1}$. El cruce de esta información permitió examinar la relación existente entre la localización de conjuntos de vivienda social y el desarrollo social. Cabe apuntar que esta metodología permite lograr una mirada general sobre estos efectos, pero no fue diseñada para estudiar situaciones a microescala. Por ejemplo, la literatura ha asumido que la construcción de viviendas sociales conlleva un descenso del IDS (Zunino y Hidalgo, 2009); sin embargo, esta situación no se observa en aquellos casos que se construyan, por ejemplo, condominios cerrados y aislados en lugares privilegiados localizados en comunas pobres periféricas. El lector debe estar atento a no tomar una visión determinista que argumente, por ejemplo, que la construcción de conjuntos de vivienda social conlleva necesariamente un descenso en los valores del IDS. Si bien puede existir una relación de este tipo a escala general, esto no implica que se deben obviar situaciones particulares como aquellas originadas por la construcción de enclaves para habitantes pudientes en comunas pobres.

Una vez concluida esta primera fase del estudio se procedió a analizar las relaciones de poder involucradas en las transformaciones territoriales encontradas. Se definieron, en primer lugar, tres escalas verticales de análisis: el nivel del sistema social, el nivel de la estructura social y el nivel del episodio (Clegg, 1989)². El primer nivel de análisis es el más abstracto y corresponde al "sistema social", esto es, aquel ámbito de influencia definido por el sistema político e ideológico vigente. El segundo nivel de análisis corresponde a aquel ámbito entre los individuos y el sistema social que queda definido a partir del accionar de agentes, individuales o institucionales, que sientan las bases para el desarrollo urbano en la escala regional y comunal. El tercer nivel de análisis corresponde a aquel del episodio definido operativamente a partir de las prácticas sociales más inmediatas. Se entenderá que los instrumentos de planificación territorial son aquellos que facilitan y permiten el ejercicio del poder, en tanto definen el conjunto de posibilidades y restricciones que enfrentan los actores operando a niveles inferiores. En este trabajo, los actores sociales son conceptualizados también como los instrumentos del poder: es sólo a través de éstos que el ejercicio del poder adquiere una dimensión concreta y objetivable.

1 El Índice de Desarrollo Socioeconómico se construyó sobre la base de tres tipos de indicadores o dimensiones: bienes suntuarios, nivel de estudio de la población de más de 25 años y calidad de la vivienda. El primero de ellos consideró para 1992, 9 variables y para 2002, 11. En este último caso estas fueron: auto particular, lavadora, camioneta particular, microonda, moto particular, refrigerador, teléfono red fija, televisor a color, video grabador, Internet y televisión por cable. En el caso de la dimensión "educación" ella estuvo compuesta por 5 categorías: humanidades, educación media, centro de formación técnica, instituto profesional y universidad. Las variables de calidad de la vivienda fueron: techo, piso y pared, que el censo detalla a partir de los materiales utilizados en su construcción. Posteriormente se llevó a cabo la estandarización de los datos, con el fin de homogeneizar los valores y entregarle el mismo peso a cada subíndice. La formula de la estandarización es la siguiente: valor máximo-valor mínimo/valor de la variable - valor mínimo. Finalmente, por cada distrito se sumaron los tres valores estandarizados de cada dimensión considerada, obteniendo el Índice de Desarrollo Socioeconómico para cada uno de los distritos de las comunas que comprenden el área metropolitana de Santiago. Los valores más altos expresan mayores niveles de desarrollo socioeconómico. El conjunto de datos para realizar dicho cálculo se obtuvo a través REDATAM, definido como un sistema informático para recuperar datos censales en áreas menores (Ver Hidalgo y Borsdorf, 2005).

2 Clegg denomina al nivel de la estructura social como el nivel de integración. Se prefiere hablar del nivel de la estructura social para mantener la coherencia de los postulados y terminología de Giddens (1984) en su teoría de la estructuración. 
Para analizar las relaciones de poder entre actores operando en distintas escalas geográficas se recurrió a la noción de "reglas sociales" como herramienta heurística para entender la forma en que los agentes sociales se involucran en los procesos de decisión (ver Ostrom, 1996). Para ello se consideraron las distintas posiciones desde las cuales se intenta influir en el proceso de decisión política (reglas de posición), cómo estas posiciones entran o salen (reglas de borde), la capacidad para afectar los resultados que tiene cada una de las posiciones (reglas de alcance), el conjunto de normas formales que cada posición tiene a su alcance (reglas de autoridad), cómo se toman las decisiones (reglas de agregación), cómo la información puede ser manipulada, distribuida y ocultada (reglas de información) y cómo los costos y beneficios del desarrollo urbano son distribuidos entre una población dada (reglas de distribución de costos y beneficios). Estas mismas reglas fueron utilizadas para leer sistemáticamente los procedimientos para elaboración y aprobación de los instrumentos de planificación territorial, en tanto instrumentos de poder que sienta las bases para el accionar social (ver Ostrom, 1986; Zunino 2006; Zunino \& Hidalgo, 2009).

Para el caso del primer nivel de análisis (el nivel del sistema social), y considerando que analizar exhaustivamente el conjunto de posibilidades y restricciones que derivan del sistema social va mucho más allá que los límites de este trabajo, se tomó como un parámetro independiente (constante) y se caracterizó sobre la base de una lectura de las reglas sociales implícitas. Para ello se recurrió a investigaciones previas realizadas por diversos autores (Carruthers, 2001, Silva, 1996; Silva, 2006; Silva, 1998; Valdés, 1995; Zunino, 2006).

En la segunda escala de trabajo se siguió una estrategia metodológica consistente en dos etapas: 1) a partir de la base de información secundaria (leyes y reglamentos) se analizaron basadas en las reglas sociales de Ostrom los procedimientos seguidos para la elaboración y promulgación de los Planes de Desarrollo Urbano y de los Planes Reguladores comunales; 2) se aplicaron entrevistas semiestructuradas guiadas por las reglas sociales definidas por Ostrom (1986) a un actor estratégico operando a nivel estructural en cada una de las comunas que comprende este estudio. Por "actor estratégico" entendemos aquel agente que opera en el gobierno local (municipal) que tienen el suficiente alcance para influir en los resultados de una política pública. Nos referimos concretamente a Administradores Municipales, Directores de Departamento de Obras y asesores de Alcaldes, todas estas posiciones que disponen de canales formales e informales para hacer valer sus puntos de vista y cuentan con acceso a información estratégica en el proceso de aprobación de cualquier política pública a escala local (municipal).

Para el nivel del episodio interesaba reconocer cómo los representantes de la comunidad se involucraron en la elaboración de los instrumentos de planificación territorial; apuntando directamente al estudio de los mecanismo de participación ciudadana y el grado en que la comunidad local puede no sólo hacer oír su voz, sino también tener incidencia en el resultado final (regla de agregación). También interesaba conocer los principales problemas que afectaban la comunidad, la organiza- 
ción interna que se han dado y los vínculos que mantienen con la autoridad. Estos elementos están dirigidos a evaluar su capacidad para ejercer el poder. Se realizaron dos entrevistas abiertas en cada comuna los años 2007 y 2008, una con un representante de una organización vecinal de un Conjunto de Vivienda Social y otra con un vecino que sin ocupar una posición formal contaba con cierto liderazgo ante la comunidad (método reputacional).

El hecho de que todos los niveles funcionales fueran analizados utilizando la misma herramienta heurística (reglas sociales), permite establecer las relaciones entre escalas geográficas, distanciándonos de una geografía plana y descriptiva.

\section{Poder y geografía sociorresidencial}

\section{Dinámica social-residencial en Santiago y Valparaíso}

Las áreas metropolitanas de Santiago y Valparaíso concentran más de seis millones y medio de habitantes, es decir, cerca del $44 \%$ de la población nacional, agrupando alrededor de la mitad de la población urbana del país. En ellas están ocurriendo importantes procesos de transformación socioespaciales que incluyen: suburbanización, periurbanización, policentralización, fragmentación intraurbana y el desarrollo de proyectos inmobiliarios en el área rural-urbana.

Lo que ocurre en dichas áreas debe ser analizado a la luz de la especificidad del caso chileno. De este esta forma, no se puede hacer omisión de las transformaciones sociales y productivas que ha vivido el país en las últimas décadas. Desde inicios de la década de 1990 se pasa de un Producto Interno Bruto (PIB) per cápita de alrededor de USD 6.000 a uno que en la actualidad asciende a cerca de USD14.000. Esta más que duplicación de este indicador en casi veinte años mudó de forma notable la composición socioeconómica de nuestra sociedad y, por extensión, la de nuestras ciudades, transformando los modos de consumo y el acceso a determinados bienes y servicios de parte importante de la población del país.

El análisis de la información de los censos de 1992 y 2002, así como las encuestas de caracterización económica nacional (CASEN) indican progresivos cambios en la fuerza laboral que componen los distintos grupos sociales, aumentos en el nivel de ingreso de la población y disminución de la pobreza. Algunos estudios se refieren a la tendencia a la "medianización de la sociedad", como el estudio de De Mattos, Riffo, Yáñez y Salas (2007) para el área metropolitana de Santiago, donde infieren, según a la utilización de datos censales, una tendencia al fortalecimiento de los grupos medios, que calza a su vez con lo informado por la evolución de los resultados de la Encuesta Caracterización Socioeconómica Nacional (CASEN). Dicho instrumento informa de una importante reducción de la pobreza en el país, del 36\% de la población nacional a comienzos de los años noventa a un 13,7\% en 2006. Sin embargo, en el mismo estudio anteriormente citado se destaca la "regresiva distribución del ingreso", expresada a nivel nacional en una "relación 18 a 1 entre el $20 \%$ de los hogares más ricos y el 20\% de los hogares más pobres” (De Mattos, Riffo, Yáñez y Salas, 2007, p. 97), que se ha mantenido prácticamente inmutable en el período 1900-2003. 
Sin embargo, es preciso tener presente que en otros países con similar estructura socioeconómica existente en Chile, las desigualdades son producto de la existencia de una población extremadamente pobre, generándose una realidad urbana que presenta una marcada dicotomía entre áreas urbanas extremadamente bien dotadas y residencias de alto valor con barriadas populares en donde la población vive en extrema pobreza y, en muchos casos, conviviendo con diversas patologías urbanas como tráfico de drogas, delincuencia y violencia. Cabe apuntar que la desigualdad en Chile es consecuencia, fundamentalmente, del 1\% de la población más afluente, no de una situación generalizada de extrema pobreza.

Con todo, en el caso chileno, existen y se mantienen por tanto desigualdades que marcan a la sociedad que habita en el país y sus ciudades. Esta condición macro puede ser un marco interpretativo para el análisis de la variación del Índice de Desarrollo Socioeconómico (IDS) en las áreas metropolitanas de Santiago y Valparaíso en el periodo 1992-2002 y su relación con los desarrollos inmobiliarios asociados a conjuntos de Vivienda social y de condominios, tanto urbanos como de parcelas de agrado situados en predios rústicos.

La Figura 2, para el caso del AMS, y la Figura 3, para el caso del AMV, muestran las variaciones 1992-2002 del indicador IDS en áreas censales sin vivienda social, con vivienda social, sin condominios, con condominios y con vivienda social y condominios. La Figura 4 muestra la clasificación de las zonas censales del AMS y AMV. Para el caso de los distritos censales del AMS, cabe destacar que el IDS experimenta un fuerte incremento en las zonas censales periurbanas sin vivienda social, con condominios y con condominios y viviendas sociales. Para el caso del AMV, el mayor incremento en el IDS se observa en comunas periféricas con condominio y en zonas censales centrales con vivienda social y condominios. Lo anterior es indicativo de que la presencia de condominios tiende a ser un factor significativo en el incremento del IDS. En zonas censales con vivienda social tanto del AMS como del AMV el IDS tiende ya sea a subir o bajar levemente. De las Figuras 2 y 3 se desprende que existen diferencia en la evolución social en las áreas censales consideradas, lo cual es indicativo de factores operando a escala metropolitana y local que impiden una generalización fácil. Sin embargo, en términos gruesos, se puede colegir un aumento del IDS en gran parte de las zonas censales, sin y con condominios y con viviendas sociales y condominios al mismo tiempo. Menores variaciones y a veces levemente negativas se observan en zonas con y sin vivienda social. Así, inversiones inmobiliarias y población demandante determinan, en parte, la geografía sociorresidencial de un lugar. Al mismo tiempo la densidad de servicios, equipamientos e infraestructuras preexistentes son también elementos de valoración de un territorio y su acceso condiciona los diferentes niveles de bienestar de la población. En este sentido, las variaciones del IDS son diferentes en los distintos espacios de las periferias de las áreas metropolitanas de Santiago y Valparaíso. Sus grados de variación se explican precisamente por la localización de esos conjuntos y por las características de los lugares donde se emplazan tanto los condominios como las viviendas sociales y, finalmente, lo más relevante, por las condiciones socioeconómicas de sus residen- 
tes. La llegada de habitantes con mayores ingresos que domina en los condominios provocará subidas significativas del IDS y la llegada de población pobre de viviendas sociales, generará el efecto contrario (ver Figuras 2 y 3 ).

FIGURA 2 |Variación IDS en zonas censales del área metropolitana de Santiago y su periferia

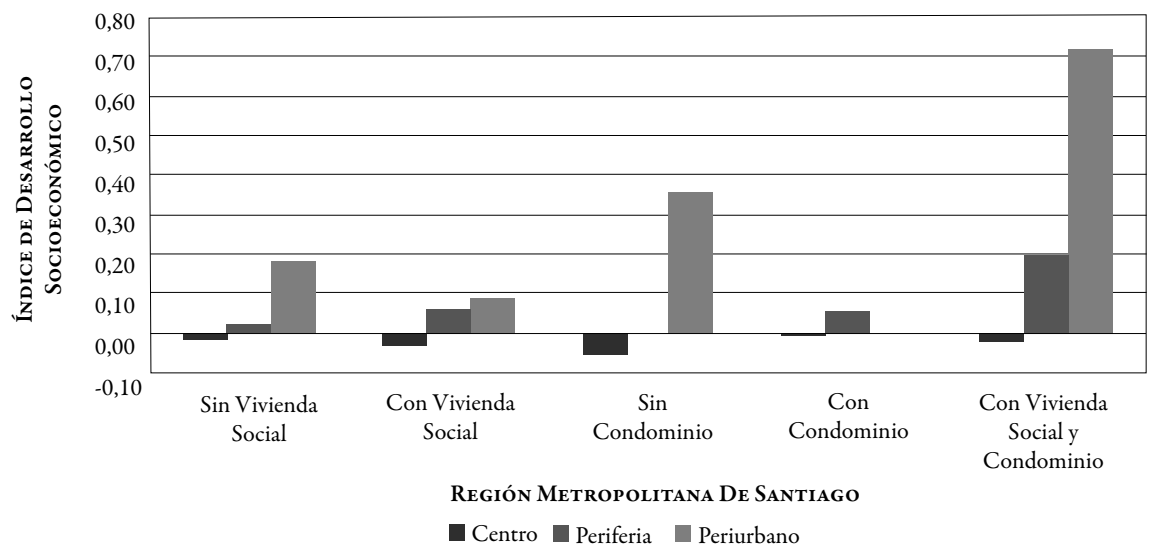

FUENTE ELABORACIÓN PROPIA.

FIGURA 3 | Variación IDS en zonas censales del área metropolitana de Valparaíso y su periferia

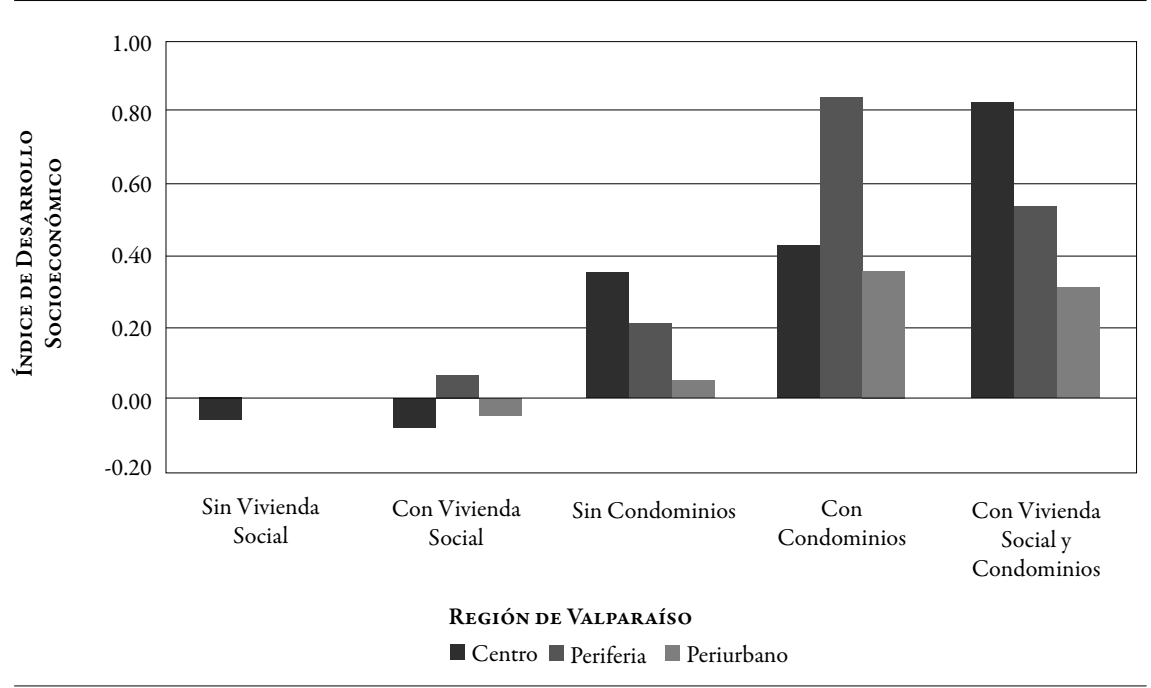

FUENTE ELABORACIÓN PROPIA. 
FIGURA 4 |Clasificación de comunas del AMV y AMS en centrales, periféricas y periurbanas

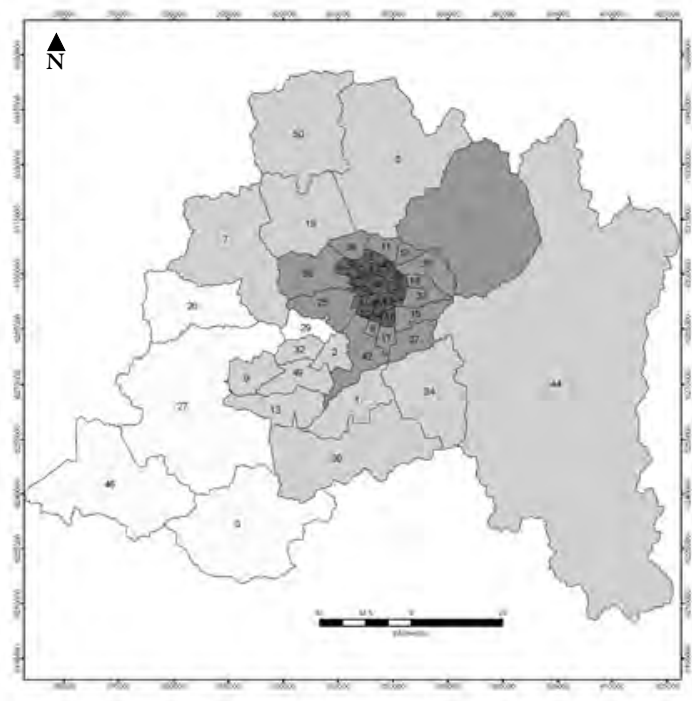

Región Metropolitana
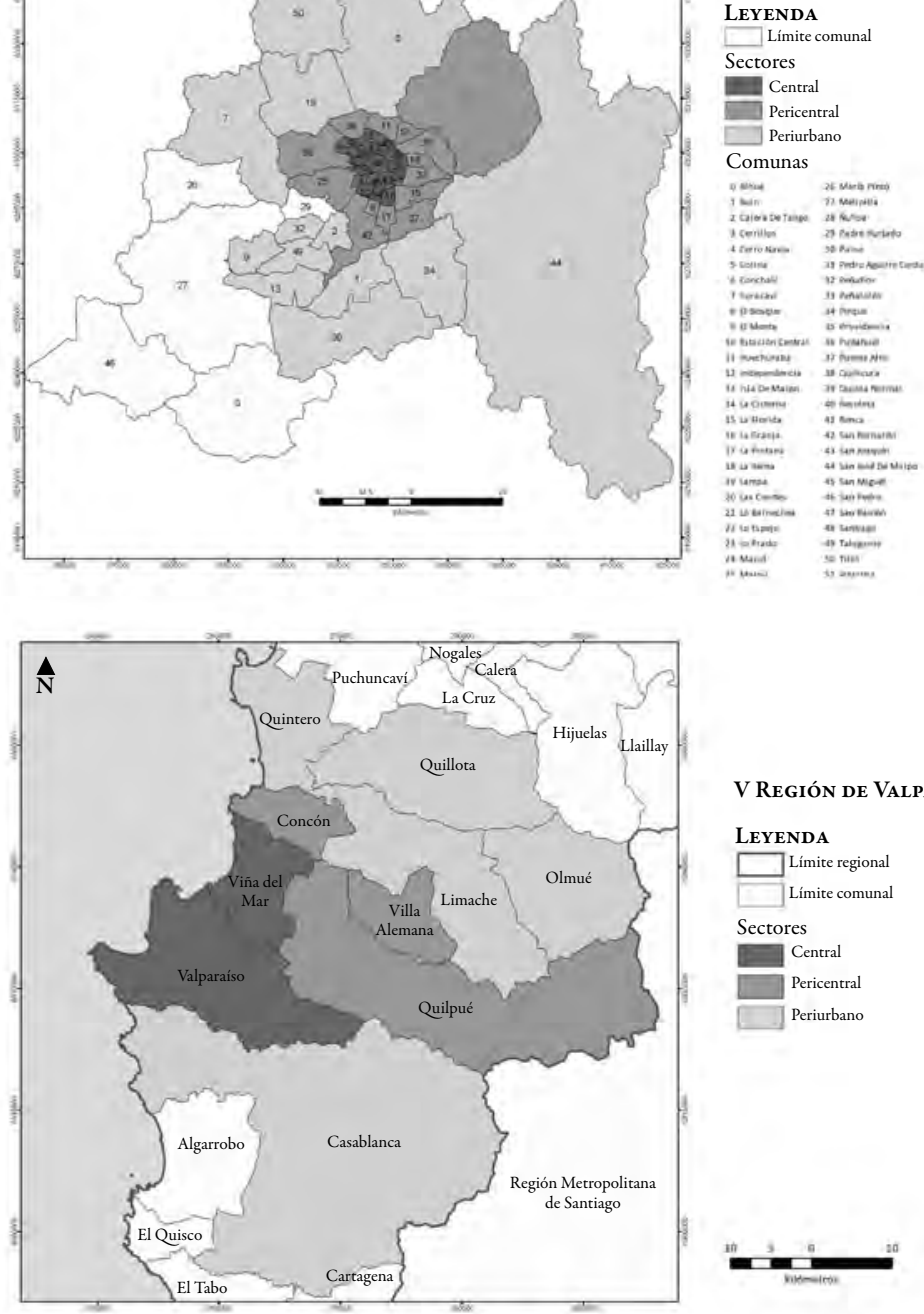

V REgión de VALPARAíso

\section{LEYENDA}

$\square$ Limite regional

Limite comunal

Sectores

Central

Pericentral

Periurbano

FUENTE ELABORACIÓN PROPIA.

Esto último, en todo caso, no funciona de modo mecánico y tampoco constituye una ley, sobre todo en el caso de las viviendas sociales, las que si se emplazan en localizaciones que posibilitan la accesibilidad a bienes, servicios, mercado laboral, entre otros, darán como resultado variaciones positivas del IDS. Al mismo tiempo, 
existen también otras dinámicas, no consideradas en este estudio, donde se generan cambios en el IDS y que no están asociados a conjuntos residenciales como los aquí considerados. Dichas modificaciones también encierran dinámicas de movilidad de la población que puede estar influida tanto por los procesos socioeconómicos globales del país, asociados a un aumento de la riqueza, a las desigualdades que existen en la distribución de los ingresos y al acceso a las oportunidades de desarrollo y mercado laboral.

Lo anterior informa del marco general de cambio socioespacial vivido en la periferia de las áreas metropolitanas de Santiago y Valparaíso, cuya dinámica interna de las relaciones entre los distintos agentes que participan de la construcción del espacio residencial involucrado en los condominios y viviendas sociales será analizado en los puntos siguientes.

\section{La dimensión multiescalar del poder}

\section{El sistema social}

Las radicales reformas neoliberales implementadas en el país a partir de 1980 por el gobierno autoritario (1973-1990) y continuadas con un componente más social marcado por las administraciones democráticas (1990- presente) constituirá el punto de entrada analítico. Las reformas no estaban dirigidas solamente a cambiar el aparato económico, buscaban cambiar la sociedad chilena para siempre. En términos generales, este proyecto mesiánico cambió la mentalidad de los individuos involucrados en la toma de decisiones en cuanto a cómo se enmarcaban los problemas. En Chile el sujeto ha sido reinterpretado. Antes de 1973, el sujeto era entendido como una figura política que intentaba avanzar la acción colectiva como medio para alcanzar sus fines; hoy en día la acción del sujeto y sus decisiones están basadas en una fuerte individualización, lo cual tiene su expresión en la racionalidad económica que domina a la sociedad chilena (Silva, 1996; Olavarría, 2003; Zunino, 2006).

La reinvención del sujeto fue posible gracias a que la capacidad de las elites políticas y económicas para afectar los resultados de los procesos de decisión se incrementaron (reglas de posición y alcance), es decir, se dio una tecnificación del proceso de toma de decisiones. A ello se suma el surgimiento de los tecnócratas como eslabón esencial en el proceso político (reglas de posición y agregación), y la atomización de importantes segmentos de la sociedad (ver Silva, 1996 y 1998).

Siguiendo a Olavarría (2003), el carácter autoritario de la Constitución de 1980, aprobada durante el gobierno militar, representaba una eficiente herramienta política para incrementar el poder de las elites, proceso que estuvo basado en el desmantelamiento del tradicional sistema de partidos políticos. Tecnocracia, individualización y reformas políticas fueron los vehículos para debilitar la participación en asuntos públicos. Para evitar la acción colectiva de resistencia, el gobierno autoritario reforzó la capacidad que tenían las elites para ejercer el poder. Así, este sector social paulatinamente tomó control de los principales nodos de decisión política (Carruthers, 2001; Valdés, 1995), monopolizó la producción de información e hizo 
uso del aparato del Estado para avanzar en sus fines. Las elites lograron tal alcance que se convirtieron en el principal referente para comandar el desarrollo social, económico y territorial del país. La capacidad que tienen las elites para ejercer el poder es hoy aún fuerte, no obstante que su configuración interna ha cambiado por la incorporación de profesionales cercanos a la coalición política en el poder desde 1990. Asociado con la consolidación de una elite técnica económica, el lenguaje de los economistas ha penetrado profundamente al cuerpo social. Siguiendo a Valdés (1995), los principios macroeconómicos se han erigido como referentes sacrosantos.

Cabe apuntar, sin embargo que el "poder de las elites" no constituye una situación reciente o que responde mecánicamente a las reformas neoliberales implementadas a mediados de la década de los setenta. Desde el tiempo colonial y a través de toda la vida republicana las elites de turno han ejercido el poder en distintos contextos sociales e ideológicos. Lo que cambia a partir de las reformas neoliberales es la forma de ejercer el poder, expresado particularmente en el surgimiento de una mentalidad tecnocrática neoliberal que, en parte, ha sustituido o permanece en tensión con el poder político. Por cierto, en muchos casos el poder de la tecnocracia va a la par con el poder político, lo cual ha generado conflictos en distintos gobiernos en Chile.

En el caso particular de las reformas neoliberales en Chile, dicho proceso social tuvo evidentes efectos sobre las reglas de alcance, autoridad e información. En los episodios de toma de decisiones sólo la información técnica basada en la ciencia positivista es considerada como válida, permaneciendo el proceso al margen del escrutinio público. De hecho, durante las últimas décadas la burocracia estatal se ha apoyado insistentemente en argumentos de tipo técnico, creando nodos de poder en el gobierno de la nación. La forma tecnocrática, elitista y autoritaria en que se toman las decisiones en Chile ha sido analizada por un número importante de investigadores (Silva, 1996 y 1998; Zunino, 2006; Zunino \& Hidalgo, 2009).

El estilo de gobierno impuesto por el gobierno militar y reproducido, en lo medular, por los gobiernos democráticos ha marginalizado a importantes segmentos de la población de los asuntos que les afectan. Siguiendo a Olavarría (2003), los asuntos públicos son administrados desde "arriba hacia abajo" a través de acuerdos entre miembros de las elites que son tomados sin considerar la participación ciudadana. Cabe apuntar, en concordancia con el párrafo anterior, que esto no significa que esta forma de gobernar sea algo nuevo en Chile: apuntamos más a los mecanismos y reformas específicas que permitieron reproducir esta modalidad de ejercer el poder. En el contexto espacio-temporal e ideológico en que se inserta esta investigación, los asuntos sociales no son tratados como cuestiones de orden político, tan sólo como asuntos de orden técnico. Este escenario afecta a las organizaciones civiles que operan a nivel de los episodios: la población pobre se ve obligada a actuar en forma fragmentada, rompiendo el otrora fuerte movimiento poblacional. Para Taylor (2003), uno de los objetivos de las reformas políticas iniciadas por el gobierno militar era atomizar al sector popular de modo de impedir la resistencia colectiva. A nuestro juicio, esto continúa siendo válido en Chile hasta el día de hoy. 


\section{El Nivel de la Estructura Social}

La Ley General de Urbanismo y Construcciones promulgada en 1975 regula la planificación urbana a distintos niveles. En términos formales, la planificación en Chile sigue una lógica jerárquica, consecuente con el sofocante centralismo nacional. A nivel nacional, la Política Nacional de Desarrollo Urbano define el contexto y criterio básico para la elaboración de los instrumentos de planificación para escalas menores. Este instrumento es elaborado por el Ministerio de la Vivienda y Urbanismo -MINVU- (Regla de Posición) y su aprobación es facultad privativa del Presidente de la República (regla de agregación). A nivel regional, las directrices para regular el desarrollo urbano están contenidas en el Plan Regional de Desarrollo Urbano. Este instrumento es elaborado por la Secretaría Regional Ministerial del Ministerio de Vivienda y Urbanismo -SEREMI-MINVU- (regla de posición) y su aprobación recae sobre el intendente regional (regla de agregación), nombrado por la oficina nacional del MINVU y el Presidente de la República (regla de borde). En la escala local, los planes de uso del suelo son elaborados por cada una de las municipalidades y deben ser aprobados por el SEREMI-MINVU, posición nombrada por el Presidente de la República. La Figura 5 muestra la situación en el área de estudio. Buena parte de las comunas no cuenta con planes locales de uso del suelo, por lo cual cobran preponderancia los instrumentos definidos en la escala regional, como los Planes de Desarrollo Regional e instrumentos de macrozonificación asociados; esto nos muestra, otra vez, el centralismo que impera en materia de desarrollo urbano.

Así, la centralización de los procesos de decisión política en materia de desarrollo urbano es bastante evidente. Todas las posiciones que tienen un alcance efectivo son nombradas por el Presidente de la República (reglas de borde). Para controlar los procesos de desarrollo urbano, el MINVU hace uso de una gama de reglas sociales de autoridad que le permite a esta instancia fijar prioridades para el SEREMIMINVU, manejar el presupuesto, aprobar instrumentos de planificación territorial, y controlar la producción y distribución de la información. De manera similar, el MINVU ha establecido un conjunto de canales informales para comunicarse con el sector privado, lo cual permite a los inversionistas privados y desarrollistas inmobiliarios influir decisivamente en asuntos urbanos estratégicos (Zunino, 2006).

La política de vivienda también es responsabilidad del MINVU. A pesar de que las políticas urbanas y las políticas de vivienda social debiesen estar estrechamente vinculadas - dados los impactos que tiene la vivienda social sobre el sistema urbano- la política habitacional cae bajo la responsabilidad de un Departamento con atribuciones propias que opera formalmente dentro de la estructura MINVU pero que goza de importantes grados de autonomía. La política de vivienda social chilena opera de acuerdo a un esquema de subsidio a la demanda que se logra después de un período de ahorro previo. Este requerimiento es funcional al sistema social vigente desde dos puntos de vista. Por una parte, contribuye al parcial financiamiento de la vivienda y reduce el déficit habitacional en términos cuantitativos. Por otra, y más significativo aún, representa un canal por medio del cual el poder es ejercido sobre la población mediante la construcción progresiva del homus economicus y la progresiva domesticación del sujeto, el cual desarrolla las habilidades básicas para reproducir el sistema social a través de sus prácticas sociales diarias, la cotidianeidad (ver Giddens, 
1984). El sistema tiene varias contradicciones. A nivel discursivo el mercado ofrece la oportunidad de elección, pero, en la práctica, los beneficiados por el subsidio habitacional tienen muy poco espacio para elegir (Zunino \& Hidalgo, 2009). La provisión de vivienda social es responsabilidad del sector privado y ellos construyen en aquellas localidades donde pueden comprar terrenos comparativamente más baratos, los cuales están localizados por lo general en las áreas periféricas de la ciudad. La consecuencia es la formación de guetos de pobreza.

FIGURA 5 | Instrumentos de planificación vigentes en comunas de la periferia del AMS y AMV

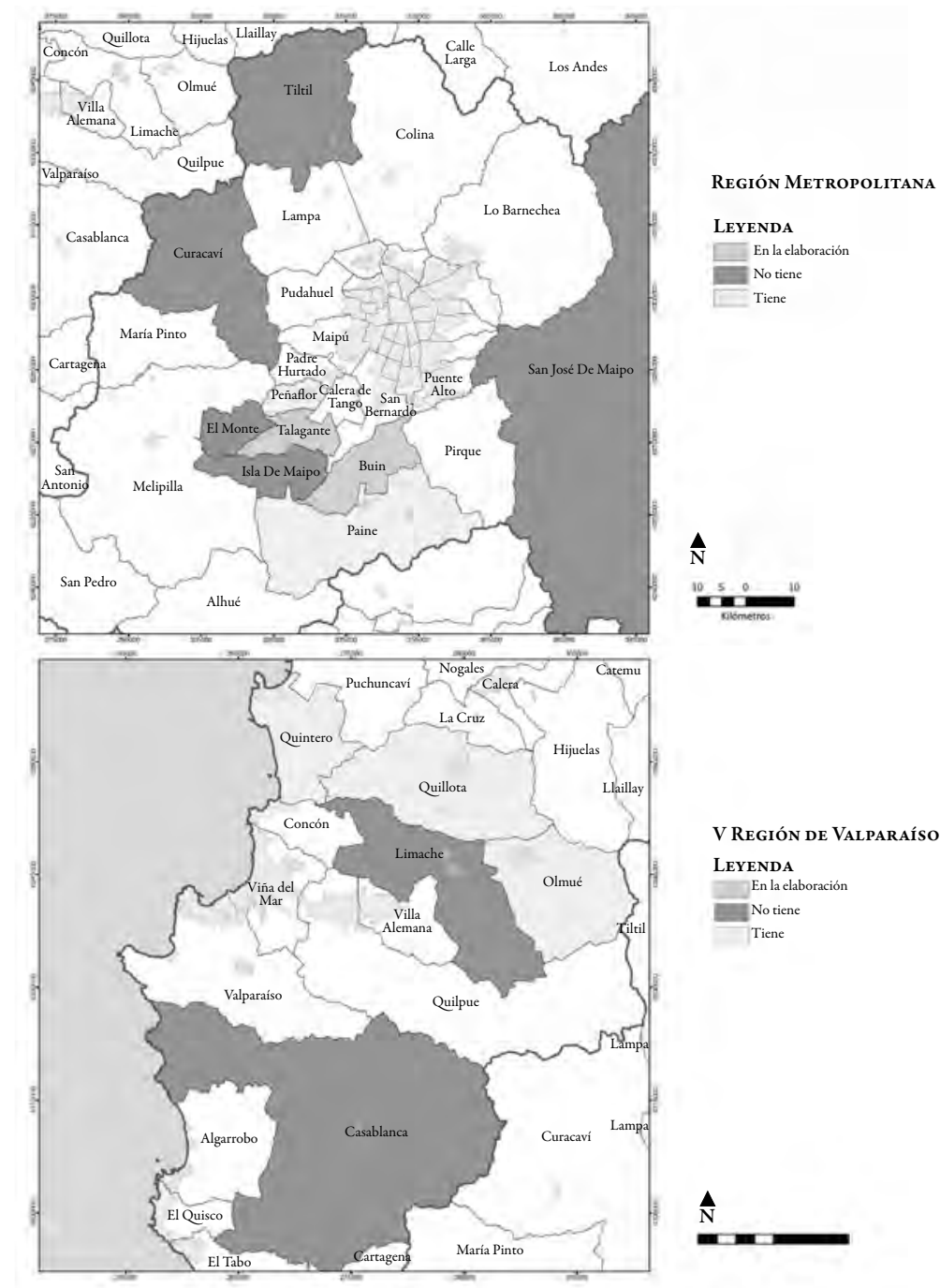

FUENTE ELABORACIÓN PROPIA. 
En los primeros años de la década de los ochenta, inversionistas inmobiliarios y los dueños del suelo lograron posiciones privilegiadas con el suficiente alcance para afectar procesos de desarrollo urbano (reglas de alcance). Efectivamente, poseían una gama de recursos como conexiones políticas, capital y manejo de información estratégica que no estaba disponible para otros participantes en el proceso de toma de decisiones. En las entrevistas efectuadas un número significativo de informantes se refirió al poder de las empresas inmobiliarias y cómo ellas actuaban despóticamente. En concreto, al menos el $40 \%$ de los personeros entrevistados mencionó la influencia de este sector en la aprobación de los planes reguladores comunales. La existencia de estos canales para ejercer influencia -que permanecen ocultos a la mayoría de los agentes urbanos- facilita el despliegue de una compleja estrategia territorial que consiste en la compra de grandes extensiones de tierra cerca de límite urbano, establecimiento de canales informales de diálogo y negociación con agentes urbanos operando en las municipalidades, y el despliegue de una estrategia de promoción y especulación urbana.

\section{Nivel de los episodios}

En este nivel de análisis resulta relevante reconocer más en detalle cómo los actores que son receptores de los impactos de los procesos de urbanización son integrados (o no) en los procesos de decisión política y cuál es su vínculo con las instancias formales de decisión encarnadas en el gobierno municipal y sus agentes.

En lo referido al grado de participación en la elaboración de los Instrumentos del Planificación Territorial de la comunidad, el Cuadro 1 sintetiza la forma de esa participación, definiendo el alcance y la capacidad de incidir en la toma de decisiones que ellos tuvieron. En la mayoría de las comunas los entrevistados manifestaron que en decisiones sobre la elaboración de los instrumentos de planificación territorial.

Así, si bien existieron instancias formales para recabar información (regla de información), las entrevistas llevadas a cabo, tanto con habitantes de complejos de vivienda social como con personeros del gobierno local y regional, no dieron luces sobre cómo estas opiniones fueron consideradas (reglas de agregación). De esta forma, el proceso de consulta a las organizaciones sociales en materias de desarrollo urbano puede entenderse como una estrategia para vestir democráticamente el accionar del gobierno en sus distintas escalas de intervención. Similarmente, las entrevistas mostraron que los inversionistas tienen canales abiertos para incidir sobre el proceso de urbanización, lo cual es posibilitado por la legislación vigente que opera en el nivel de la estructura social. Son los inversionistas y promotores inmobiliarios los que tienen la capacidad y recursos necesarios para decidir sobre la localización de los complejos de vivienda social y el nivel de equipamiento. Cabe apuntar que aún persiste un vacío en la literatura contemporánea sobre las tácticas específicas desplegadas por una gama de actores sociales para incidir en los procesos de urbanización. Esto se explica, en parte importante, por el secretismo que impera en el proceso de toma de decisiones y en donde se manifiestan relaciones de poder 
que no siempre es prudente ni conveniente - para diversos actores públicos y privados- que sean conocidas por el general de la población.

CUADRO 1 | Formas en que la opinión de los vecinos fueron tomadas en cuenta en la elaboración de instrumentos de planificación territorial - Reglas de Posición ${ }^{a}$

\begin{tabular}{|c|c|c|c|c|c|c|c|}
\hline $\begin{array}{c}\text { REGIÓN/ } \\
\text { MUNICIPALIDAD }\end{array}$ & & & & & & & \\
\hline & Comuna & \begin{tabular}{|} 
TALLERES CON \\
ORGANIZACIONES \\
VECINALES \\
VECINOS
\end{tabular} & $\begin{array}{c}\text { Cabildos } \\
\text { CoMunitarios }\end{array}$ & $\begin{array}{l}\text { REUNIONES } \\
\text { INFORMALES }\end{array}$ & Encuestas & $\begin{array}{l}\text { Votación No } \\
\text { VinCulante }\end{array}$ & Ninguna \\
\hline \multirow[t]{8}{*}{ MEtropolitana } & Tiltil & $\mathrm{x}$ & & & & & \\
\hline & Curacaví & & $\mathrm{x}$ & $\mathrm{x}$ & & & \\
\hline & Peñaflor & & & & & & $\mathrm{x}$ \\
\hline & El Monte & & & & & & $\mathrm{x}$ \\
\hline & Talagante & $\mathrm{x}$ & & $\mathrm{x}$ & $\mathrm{x}$ & & \\
\hline & Buin & $\mathrm{x}$ & & & & & \\
\hline & Paine & & & $\mathrm{x}$ & & & \\
\hline & $\begin{array}{l}\text { Isla de } \\
\text { Maipo }\end{array}$ & & & $\mathrm{x}$ & & & \\
\hline \multirow[t]{5}{*}{ ValParaíso } & Quintero & & & $\mathrm{x}$ & & $\mathrm{x}$ & \\
\hline & Quillota & & & $\mathrm{x}$ & $\mathrm{x}$ & & \\
\hline & Olmué & & & $\mathrm{x}$ & & & \\
\hline & Limache & & & & & & $\mathrm{x}$ \\
\hline & Casablanca & & $\mathrm{x}$ & & & & \\
\hline Total & & 3 & 2 & 7 & 2 & 1 & 3 \\
\hline
\end{tabular}

a ENTREVISTAS EFECTUADAS 2007 y 2008 CON POSICIONES ESTRATÉGICAS OPERANDO EN EL GOBIERNO LOCAL (MUNICIPALIDAD)

FUENTE ELABORACIÓN PROPIA.

La ausencia de una participación efectiva también queda reflejada a través de los datos contenidos en los Cuadros 2 y 3. Si bien existen once juntas de vecinos constituidas formalmente, sólo cinco de ellas están "activas", entendiendo por ello que existe una membrecía definida y que existen reuniones regulares (al menos una al mes). Sin embargo, las entrevistas muestran que esta "actividad" no implica que la población en general se sienta empoderada y partícipe del desarrollo urbano. Las entrevistas recogieron una variada gama de críticas a la gestión del gobierno local, desde cuestiones de orden doméstico hasta aspectos más estructurales. Asimismo, seis juntas de vecinos presentan baja o nula actividad y en la Comuna de Casablanca no existen instancias formales de asociatividad. Los aspectos que se desprenden del Cuadro 3 son reforzados al considerar que en 10 de las 13 comunas que comprende el área de estudio el contacto de los habitantes de conjuntos de vivienda social es inexistente o sólo se da para solucionar aspectos puntuales que afectan a algún miembro de la comunidad. 
CUADRO 2 |Forma de asociatividad en los complejos de vivienda social - Reglas de Posición ${ }^{\mathrm{a}}$

\begin{tabular}{|c|c|c|c|c|}
\hline REgión & MUNICIPALIDAD & $\begin{array}{c}\text { JUNTA DE } \\
\text { VECINOS } \\
\text { ACTIVA }\end{array}$ & $\begin{array}{c}\text { JunTA DE VECINOS } \\
\text { CON BAJA/Nula } \\
\text { ACTIVIDAD }\end{array}$ & $\begin{array}{c}\text { NO EXISTEN } \\
\text { INSTANCIAS } \\
\text { FORMALES DE } \\
\text { ASOCIATIVIDAD }\end{array}$ \\
\hline \multirow{8}{*}{$\begin{array}{c}\text { REGIÓN } \\
\text { METROPOLITANA }\end{array}$} & Tiltil & & $\mathrm{x}$ & \\
\hline & Curacaví & $\mathrm{x}$ & & \\
\hline & Peñaflor & $\mathrm{x}$ & & \\
\hline & El Monte & & $\mathrm{x}$ & \\
\hline & Talagante & $\mathrm{x}$ & & \\
\hline & Buin & & $\mathrm{x}$ & \\
\hline & Paine & $\mathrm{x}$ & & \\
\hline & Isla de Maipo & $\mathrm{x}$ & & \\
\hline \multirow[t]{5}{*}{$\begin{array}{l}\text { V REGIÓN DE } \\
\text { VALPARAÍSO }\end{array}$} & Quintero & & $\mathrm{x}$ & \\
\hline & Quillota & & $\mathrm{x}$ & \\
\hline & Olmué & & $\mathrm{x}$ & \\
\hline & Limache & $\mathrm{x}$ & & \\
\hline & Casablanca & & & $\mathrm{x}$ \\
\hline Total & & 5 & 6 & 1 \\
\hline
\end{tabular}

a ENTREVISTAS EFECTUADAS 2007 y 2008 CON REPRESENTANTES DE ORGANizACIONES VECINALES DE COMPLEJOS DE VIVIENDA SOCIAL.

FUENTE ELABORACIÓN PROPIA.

CUADRO 3 | Relación entre los habitantes de conjuntos de vivienda social con autoridades del gobierno local para solucionar problemas - Reglas de Agregación ${ }^{\mathrm{a}}$

\begin{tabular}{|c|c|c|c|c|}
\hline REgIón & Municipalidad & $\begin{array}{l}\text { Contactos } \\
\text { Frecuentes }\end{array}$ & $\begin{array}{c}\text { CONTACTO PARA } \\
\text { SOLUCIONAR ASPECTOS } \\
\text { PUNTUALES }\end{array}$ & Ninguna \\
\hline \multirow[t]{8}{*}{ Región Metropolitana } & Tiltil & & $\mathrm{x}$ & \\
\hline & Curacaví & $\mathrm{x}$ & & \\
\hline & Peñaflor & $\mathrm{x}$ & & \\
\hline & El Monte & & & $\mathrm{x}$ \\
\hline & Talagante & & & $\mathrm{x}$ \\
\hline & Buin & & & $\mathrm{x}$ \\
\hline & Paine & & $\mathrm{x}$ & \\
\hline & Isla de Maipo & & $\mathrm{x}$ & \\
\hline \multirow[t]{5}{*}{ V REgión de VALParaíso } & Quintero & & & $\mathrm{x}$ \\
\hline & Quillota & & $\mathrm{x}$ & \\
\hline & Olmué & & $\mathrm{x}$ & \\
\hline & Limache & $\mathrm{x}$ & & \\
\hline & Casablanca & & $\mathrm{x}$ & \\
\hline TotaL & & 3 & 6 & 4 \\
\hline
\end{tabular}

a ENTREVISTAS EFECTUADAS 2007 Y 2008 CON REPRESENTANTES DE ORGANIZACIONES VECINALES DE COMPLEJOS DE VIVIENDA SOCIAL.

FUENTE ELABORACIÓN PROPIA. 
La autoridad política muestra escaso interés por modificar la dinámica de toma de decisiones existente, a pesar de contar con reglas formales que le permitirían avanzar en esta dirección. Desde nuestra perspectiva, la mentalidad neoliberal ha penetrado profundamente en los granos más finos de la sociedad, naturalizando las leyes de mercado. Un rol mayor del Estado como agente de cambio se ve como una amenaza al statu quo imperante. Así, de las diez municipalidades periféricas que contempla este estudio, encontramos que todos los planes reguladores estaban desactualizados y en tres no existía siquiera un plan de desarrollo comunal que fijase los principios para la elaboración de planes de uso del suelo.

En tanto los alcaldes y consejeros comunales son posiciones elegidas por sufragio universal (regla de borde), el municipio constituye el nexo más inmediato y real entre la autoridad política y los ciudadanos. Es por esto que la escala local es el ámbito de acción esencial para construir formas democráticas y participativas de gestión territorial. La comunidad local, en general, y los habitantes de vivienda social, en particular, operan y sus vidas transcurren enmarcadas - pero no determinadas- por el andamiaje institucional y las relaciones de poder que lo sostienen. En el Chile de hoy nos encontramos con pobladores marginales no tan sólo en términos socioterritoriales, sino que también políticos. Ciudadanos que permanecen en la sombra, ajenos al accionar de una variada gama de redes sociales que operan informalmente para avanzar fines determinados. A un nivel general podemos distinguir un Estado que intenta legitimarse a través de formas pseudodemocráticas de participación y con agentes privados que hacen uso de los diversos canales que están abiertos para lucrar con la pobreza. Con todo, no podemos atribuir la situación descrita a la presencia de una macroestructura de poder que se "condensa" en un determinado tipo de andamiaje institucional. En tanto agentes estructurados, los actores locales tienen la posibilidad de resistir; efectivamente, el Estado es permeable y sujeto a cambios, ya sean graduales o abruptos. Así lo muestra la historia. Chile carece de una "cultura de la participación", situación de la cual todos somos responsables: dominados, dominadores y cualquier arquetipo intermedio. Es necesario finalmente puntualizar que nuestra interpretación es una generalización; en muchos lugares encontramos especificidades que escapan lo que aquí hemos descrito. Si bien podemos afirmar la existencia de una tendencia social generalizable; el análisis de lo particular, lo único, lo recóndito escapa a los confines de este trabajo.

\section{A modo de conclusión}

En términos generales, el IDS se incrementa en gran parte de las zonas censales, sin y con condominios y con viviendas sociales y condominios al mismo tiempo. Menores variaciones y a veces levemente negativas se observan en zonas con y sin vivienda social. Dado que intervienen elementos operando a escala local y una particular arquitectura del poder, no resulta fácil -ni útil- llegar a grandes generalizaciones. Un entendimiento más amplio del fenómeno urbano requiere analizar la conjunción entre poder y territorio. Si bien en términos generales el régimen neo- 
liberal chileno trae aparejado un conjunto de reglas sociales que limitan el ejercicio efectivo de la democracia participativa en la esfera local, los agentes locales retienen la capacidad de optar entre distintos cursos de acción e incidir en la construcción social de la ciudad. Así, en algunas zonas censales con vivienda social el IDS ha aumentado, indicativo de la capacidad potencial del gobierno local y de la comunidad para mejorar su calidad de vida.

Por tanto, resulta útil conceptualizar el desarrollo urbano no tan sólo como una configuración visible sujeta a variaciones espacio-temporales, sino también como el resultado de un proceso social que da origen a un determinado andamiaje institucional, el cual es sostenido por relaciones de poder que les son propias y que son posibles de identificar. Este posicionamiento teórico permite aproximarse al hecho urbano de forma más integral, reconociendo los elementos y relaciones sociales que están detrás de toda configuración espacial. El espacio no es neutro, refleja intereses y constituye el resultado de relaciones de poder. Reconociendo la naturaleza social y política del espacio, contaremos con elementos básicos para intervenir, eventualmente, en centros neurálgicos de reproducción socioespacial. Metodológicamente hemos sugerido un camino para interpretar los procesos urbanos a partir de una mirada multiescalar, en donde el acento analítico no está puesto sólo en la forma, sino también en el andamiaje socioinstitucional en el cual se funda lo visible. Las nociones de "poder", "reglas sociales" y "agente estructurado" fueron propuestas como herramientas heurísticas para interpretar el mundo que nos rodea. Si bien estos conceptos fueron útiles para interpretar una situación que se desenvuelve en un ámbito general, queda aún mucho por avanzar para dilucidar las tácticas, estrategias y relaciones operando en escalas más acotadas.

Es por esto que sugerimos que estudios futuros aborden problemáticas urbanas a escalas mucho más detalladas, de modo de afinar el análisis y, eventualmente, reconocer particularidades locales que pueden ser el cimiento para procesos de cambio socioespacial. Substantivamente, este trabajo ha mostrado el carácter autoritario de la política urbana, en general, y de la política habitacional, en particular. Si bien estos elementos han sido reconocidos en investigaciones precedentes, este trabajo ofrece elementos empíricos fundamentales para dar solidez al análisis.IEURE 


\section{Referencias bibliográficas}

Borsdorf, A. \& Hidalgo, R. (2008). Open port -closed residential quarters? Urban structural transformation in the metropolitan area of Valparaíso, Chile. Erdkunde, No. 62, pp. 1-13.

Brain, I.; Cubillos, G. \& Sabatini, F. (2007). Integración social urbana en la nueva política habitacional. Temas de agenda pública, No. 2, pp. 1-15.

Brain, I. \& Sabatini, F. (2006). Los precios del suelo en alza carcomen el subsidio habitacional, contribuyendo al deterioro en la calidad y localización de la vivienda social. Prourbana, No. 4, pp. 2-13.

Carruthers, D. (2001). Environmental politics in Chile: legacies of dictatorship and democracy. Third World Quarterly, No. 22, pp. 343-358.

Clegg, S. (1989). Frameworks of Power. London: Sage.

Chion, M. (2002). Dimensión metropolitana de la globalización: Lima a fines del siglo XX. Eure, No. 28, pp. 71-87.

Darcy, M. (1999). The discourse of "community" and the reinvention of social housing policy in Australia. Urban Studies, No. 36, pp. 13-16.

De Mattos, C. (1999). Santiago de Chile, globalización y expansión metropolitana: lo que existía sigue existiendo. Eure, No. 25, pp. 29-56.

De Mattos, C. (2001). Metropolización y suburbanización. Eure, No. 27, pp. 5-8.

De Mattos, C. (2002a). Mercado metropolitano de trabajo y desigualdades sociales en el Gran Santiago: ¿Una ciudad dual? Eure, No. 28, pp. 51-70.

De Mattos, C. (2002b). Transformación de las ciudades latinoamericanas: ¿Impactos de la globalización? Eure, No. 28, pp. 5-10.

De Mattos, C. \& Hidalgo, R. (Eds.) (2007). Santiago de Chile. Movilidad espacial y reconfiguración metropolitana. Santiago: Eure libros - Geolibros.

De Mattos, C.; Riffo, L.; Yáñez, G. \& Salas, X. (2007). Cambios socioocupacionales y transformación metropolitana: Santiago, 1992-2002. En C. De Mattos y R. Hidalgo (Eds.). Santiago de Chile. Movilidad espacial y reconfiguración metropolitana. Santiago: Eure libros - Geolibros.

Foucault, M. (1980). Power and strategies. En C. Gordon (Ed.), Power/Knowledge: Selected Interviews and Other Writings. New York: Patheon Books.

Foucault, M. (1992). La microfísica del poder. Madrid: La Piqueta.

Foucault, M. (1995). Discipline and Punish: The Birth of the Prison. New York: Vintage.

Gendron, R. (2006). Forging collective capacity for urban redevelopment: "power to," "power over," or both? City \& Community, No. 5, pp. 5-22.

Giddens, A. (1984). The Constitution of Society: Outline of the Theory of Structuration. Cambridge: Polity Press.

Goldsmith, M. \& Larsen, H. (2004). Local political leadership: nordic style. International journal of urban and regional research, No. 28, pp. 121-133.

González, S. (2005). La geografía escalar del capitalismo. Scripta Nova, IX. Extraído el 10 de julio de 2009 de http://www.ub.es/geocrit/sn/sn-189.htm

González, S. \& Healey, P. (2005). A sociological institutionalist approach to the study of innovation in governance capacity. Urban Studies, No. 42, pp. 2055-2069.

Hamilton, D.; Miller, D. \& Paytas, J. (2004). Exploring the horinzontal and vertical dimensions of the governing of metropolitan regions. Urban Affairs Review, No. 40, pp. 147-182. 
Harvey, D. (1978). The urban process under capitalism: a framework for analysis. International Journal of Urban and Regional Research, No. 2, pp. 101-131.

Heinrichs, D.; Nuissl, H. \& Rodríguez Seeger, C. (2009). Dispersión urbana y nuevos desafíos para la gobernanza (metropolitana) en América Latina: el caso de Santiago de Chile. Eure, No. 35, pp. 104, 29-46.

Hidalgo, R. (2007) ¿Se acabó el suelo en la gran ciudad? Las nuevas periferias metropolitanas de la vivienda social en Santiago de Chile. Eure, No. 33, pp. 98, 55-75.

Hidalgo, R. \& Borsdorf, A. (2005). Barrios cerrados y fragmentación urbana en América Latina: estudio de las transformaciones socioespaciales en Santiago de Chile (1990-2000). En R. Hidalgo, R. Trumper y A. Borsdorf (Eds.). Transformaciones urbanas y procesos territoriales. Lecturas del nuevo dibujo de la ciudad latinoamericana. Santiago: Geolibros- Academia de Ciencias Austriaca y Okanagan University College.

Hidalgo, R. \& De Mattos, C. (2007). Santiago de Chile: movilidad espacial y reconfiguración metropolitana. En C. de Mattos y R. Hidalgo (Eds.). Santiago de Chile. Movilidad espacialy reconfiguración metropolitana. Santiago: Eurelibros y Geolibros.

Hidalgo, R; Borsdorf, A.; Zunino, H. \& Álvarez, L. (2008). Tipologías de expansión metropolitana en Santiago de Chile: precariópolis estatal y privatópolis inmobiliaria. Trabajo presentado en el X Coloquio Internacional de Geocrítica, Diez años de cambios en el Mundo, en la Geografía y en las Ciencias Sociales, 1999-2008. Mayo, Barcelona. Extraído el 20 de marzo de 2009 desde: http://www.ub.es/geocrit/-xcol/434.htm

Jacobs, K. \& Manzi, T. (1996). Discourse and policy change: the significance of language for housing research. Urban Studies, No. 11, pp. 543-560.

Mullin, M.; Peele, G. \& Cain, B. (2004). City caesars? Institutional structure and mayoral success in three California nities. Urban Affairs Review, No. 40, pp. 19-43.

Olavarría, M. (2003). Protected Neoliberalism. Perverse Institutionalization and the Crisis of representation in Postdictatorship Chile. Latin American Perspectives, No. 30, pp. 10-38.

Orellana, A. (2009). La gobernabilidad metropolitana de Santiago: la dispar relación de poder de los municipios. Eure Vol. 35, No. 104, pp. 101-120.

Ostrom, E. (1996). An agenda for the study of institutions. Public Choice, 3-24.

Rodriguez, A. \& Sugranyes, A. (2005). Los con techo: un desafio para la politica de vivienda social. Santiago: Ediciones SUR.

Rose, N. \& Miller, P. (1992). Political power beyond the state: problematics of government. British Journal of Sociology, No. 43, pp. 172-205.

Sabatini, F.; Cáceres, G. \& Cerda, J. (2001). Segregación residencial en las principales ciudades chilenas: Tendencias de las tres últimas décadas y posibles cursos de acción. Eure, No. 27, pp. $21-42$.

Salazar, A. (2007). La periurbanización en recomposición de los espacios rurales metropolitanos: Santiago de Chile. En C. de Mattos y R. Hidalgo (Eds.). Santiago de Chile. Movilidad espacial y reconfiguración metropolitana. Santiago: Eurelibros y Geolibros.

Silva, E. (1996). The State and Capital in Chile: Business Elites, Technocrats, and Market Economics. Boulder, CO: Westview Press.

Silva, J. P. (2006) Cultura de masas, reforma y nacionalismo en Chile 1910-1931 (review). The Americas, No. 63, pp. 174-175. 
Silva, P. (1998). Neoliberalism, democratization, and the rise of technocrats. En M. Vellinga (Ed.). The Changing Role of the State in Latin America. Boulder: Westview Press.

Swyngedouw, E. (1997). Neither global nor local. "Glocalization” and the politics of scale. En K Cox (Ed.). Spaces of globalization. Reasserting the power of the local. New York: Guilford Press.

Swyngedouw, E. (2005). Governance innovation and the citizen: the janus face of governance-beyondthe-state. Urban Studies, No. 42, pp. 1991-2006.

Taylor, M. (2003) The reformulation of social policy in Chile, 1973-2001. Global Social Policy, No. 3, pp. $21-44$.

Valdés, J. G. (1995). Pinochet's Economists. Cambridge: Cambridge University Press.

Zunino, H. M. (2002). Formación institucional y poder: investigando la construcción social de la ciudad. Eure, No. 28, pp. 103-116.

Zunino, H. M. (2005). Construyendo ciudad desde local en lo global: el caso del proyecto Ribera Norte, Concepción, Chile. Scripta Nova, IX. Extraído el 15 de octubre de 2009 desde http:// www.ub.es/geocrit/sn/sn-194-86.htm

Zunino, H. M. (2006). Power relations in urban uecision-making: neo-liberalism, 'techno-politicians' and authoritarian redevelopment in Santiago, Chile. Urban Studies, No. 43, pp. 18251846.

Zunino, H. M. \& Hidalgo, R. (2009). Spatial and socioeconomic effects of social housing policies implemented in Chile: the case of Valparaíso. Urban Geography, No. 30, pp. 514-542. 